ISSN 0976 - 6995 (Print)

ISSN 0976 - 7002 (Online)

Volume 4, Issue 2, May - August (2013), pp. 14-20

: https://iaeme.com/Home/journal/IJDMT

https://www.doi.org/10.34218/IJDMT.4.2.2013.30320130402002

\title{
IJDMT
}

(C) I A E M E

\section{DESIGN, MODELING AND ANALYSIS OF EXCAVATOR ARM}

\author{
Sachin B. Bende ${ }^{1}$, Nilesh P. Awate ${ }^{2}$ \\ ${ }^{\mathbf{1}}$ M.Tech scholar, Mechanical Engineering Department, GHRCE, Nagpur, India \\ ${ }^{2}$ Asst. Professor, Mechanical Engineering Department, GHRCE, Nagpur, India
}

\begin{abstract}
The present work concentrate on the study of the components of the excavator in order to identify the problems faced while performing the lifting and digging operations and to provide a design solution by using CAD-CAE systems.For light duty construction work, generally mini hydraulic backhoe excavators are used and mostly there are soil surfaces for excavation. So, design of backhoe excavator is critical task in context of digging force developed through actuators during the digging operation. The important criteria for the design to be safe is that, the digging forces developed by actuators must be greater than that of the resistive forces offered by the surface to be excavated. The two important factors considered during designing an excavator arm are productivity and fuel consumption. As the present mechanism used in excavator arm is subjected to torsional and bending stresses during lifting and digging operation respectively, because of which failure occurs frequently at the bucket end of the arm. So, the new mechanism of excavator arm is designed and the Pro-e software is used for making the 3D model of the excavator arm linkage. By using ANSYS workbench software static analysis of each of the excavator arm component is done at existing digging force and also at newly calculated digging force. Also the bucket volume is increased to compensate for the loss in production due to the reduction in digging force.
\end{abstract}

Keywords: Excavator arm, lifting, digging, actuators, productivity, CAD-CAE systems.

\section{INTRODUCTION}

An excavator is heavy equipment consisting of an articulated arm (backhoe), bucket and cab mounted on a pivot (a rotating platform, like a Lazy Susan) a top and undercarriage with tracks or wheels. Their design is a natural progression from the steam shovel. Excavators are intended for excavating rocks and soils. Excavators may have a mechanical or hydraulic 
International Journal of Design and Manufacturing Technology (IJDMT), ISSN 0976 6995(Print), ISSN 0976 - 7002(Online) Volume 4, Issue 2, May - August (2013), () IAEME

drive. Hydraulic excavators are the most important group of excavators. The typical hydraulic excavator of VOLVO is shown in the fig. 1.

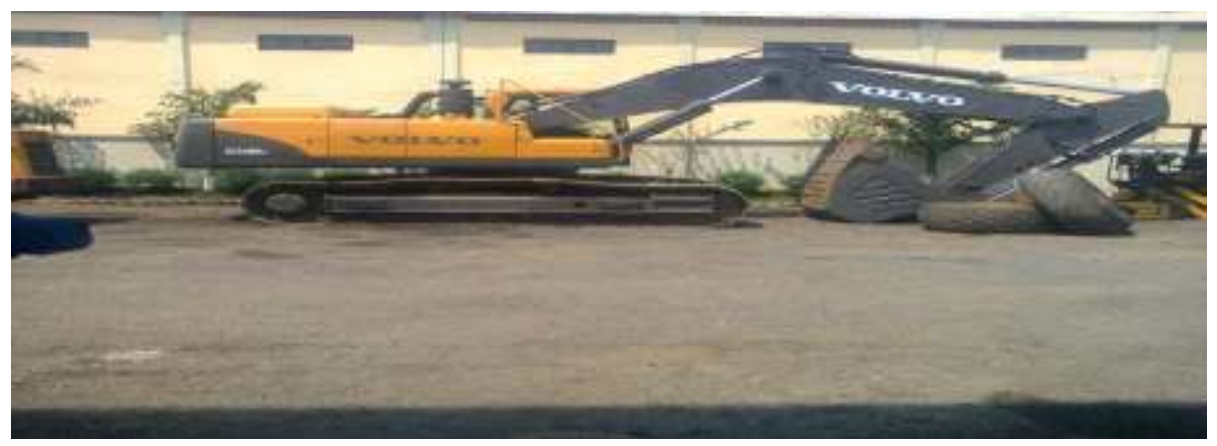

Fig.1. A typical hydraulic excavator of VOLVO

\section{DESIGN OF EXCAVATOR ARM}

\subsection{Calculation of pin diameter}

$\mathrm{F}=10,300 \mathrm{~N}, \mathrm{r}=391 \mathrm{~mm}, \mathrm{~L}=315 \mathrm{~mm}, \mathrm{P}=15.69 \mathrm{~N} / \mathrm{mm}^{2}, \mathrm{~A}=66836 \mathrm{~mm}^{2}$,

Shear stress $=42 \mathrm{~N} / \mathrm{mm}^{2}$, Bending stress $=84 \mathrm{~N} / \mathrm{mm}^{2}$.

Let, $\mathrm{d}=$ diameter of pin

Torque, $\mathrm{T}=\mathrm{F} \times \mathrm{r}=10300 \times 391=4027300 \mathrm{~N}-\mathrm{mm}$, Load, $\mathrm{W}=\mathrm{P} \times \mathrm{A}=15.69 \times 66836=1048656.8 \mathrm{~N}$

Now, Max. bending moment $=\mathrm{M}=\mathrm{WL} / 4=(1048656.8 \times 315) / 4=82581723 \mathrm{~N}-\mathrm{mm}$

Since, pin is subjected to suddenly applied load. Considering $\mathrm{K}_{\mathrm{m}}=1.5, \mathrm{~K}_{\mathrm{t}}=2$

We know that, equivalent twisting moment

$\mathrm{T}_{\mathrm{e}}=\sqrt{ }\left(\mathrm{K}_{\mathrm{t}} \times \mathrm{T}\right)^{2}+\left(\mathrm{K}_{\mathrm{m}} \times \mathrm{M}\right)^{2}=\sqrt{ }(2 \times 4027300)^{2}+(1.5 \times 82581723)^{2}$

$\mathrm{T}_{\mathrm{e}}=124134176.5 \mathrm{~N}-\mathrm{mm}$

But, $\mathrm{T}_{\mathrm{e}}=\pi / 16 \times \mathrm{d}^{3} \times$ shear stress

$124134176.5=\pi / 16 \times \mathrm{d}^{3} \times 42$

Therefore, $\mathrm{d}=246.9 \mathrm{~mm}$

we know that, equivalent bending moment

$\mathrm{M}_{\mathrm{e}}=1 / 2\left[\mathrm{~K}_{\mathrm{m}} \times \mathrm{M}+\mathrm{T}_{\mathrm{e}}\right]=1 / 2[1.5 \times 82581723+124134176.5]$

$\mathrm{M}_{\mathrm{e}}=124003380.5 \mathrm{~N}-\mathrm{mm}$

But, $\mathrm{M}_{\mathrm{e}}=\pi / 32 \times \mathrm{d}^{3} \times$ bending stress

$124003380.5=\pi / 32 \times \mathrm{d}^{3} \times 84$

Therefore, $\mathrm{d}=246.86 \mathrm{~mm}$

Taking larger of the two values, we have diameter of $\mathrm{pin}=\mathrm{d}=246.9 \mathrm{~mm}$

\subsection{Calculation for the total amount of material the bucket can lift}

Since, we have considered a light duty construction work. So, calculate for a soil surface.

Density of soil is $1463 \mathrm{~kg} / \mathrm{m}^{3}$.

For existing model,

Volume of bucket, $\mathrm{V}=0.022 \mathrm{~m}^{3}$

Total weight of soil, W= Density $\times$ Volume $=1463 \times 0.022=32.186 \mathrm{Kg}$

For proposed model,

Calculated volume of bucket, $\mathrm{V}=0.028 \mathrm{~m}^{3}$

Total weight of soil, $\mathrm{W}=$ Density $\times$ Volume $=1463 \times 0.028=40.964 \mathrm{Kg}$

Self weight of bucket $=17 \mathrm{Kg}$ 
International Journal of Design and Manufacturing Technology (IJDMT), ISSN 0976 6995(Print), ISSN 0976 - 7002(Online) Volume 4, Issue 2, May - August (2013), (C) IAEME

Now, Total load acting on bucket $=$ Self weight of bucket + Total weight of soil $=17+40.964=57.964 \mathrm{Kg}$

$=57.964 \times 9.81=568.62 \mathrm{~N}$

By using this load, the dynamic analysis will be done.

\section{MODELING}

\subsection{CAD modeling}

CAD technology is very important while designing Excavator Mechanism. Following are advantages of CAD technology :

1) To increase the productivity of the designer

2) To improve the quality of the design

\subsection{CAD/CAE softwares for Excavator mechanism design}

- PRO/E - For 3D Component Design.

- PRO/Mechanism - For Mechanism

Pro/ENGINEER is a parametric, feature based, solid modeling System. It is the only menu driven higher end software. Pro/ENGINEER provides mechanical engineers with an approach to mechanical design automation based on solid modeling technology and the features such as 3D modeling, parametric design, feature-based modeling, associativity, capturing design intent, combining features into parts, and assembly. The three dimensional model of the assembly of Excavator arm is shown in the fig. 2 .

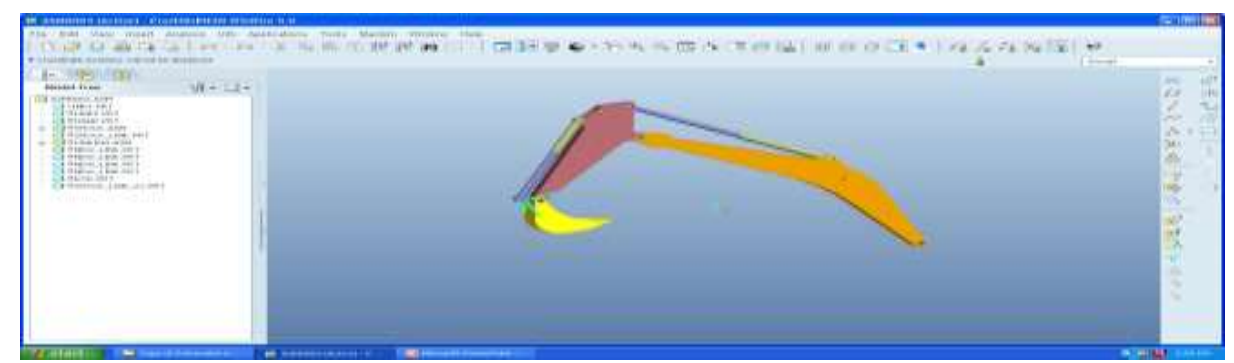

Fig.2 Excavator arm assembly

\section{FINITE ELEMENT ANALYSIS}

The finite element method (FEM), sometimes referred to as finite element analysis(FEA), is a computational technique used to obtain approximate solutions of boundary value problems in engineering. Simply stated, a boundary value problem is a mathematical problem in which one or more dependent variables must satisfy a differential equation everywhere within a known domain of independent variables and satisfy specific conditions on the boundary of the domain. Boundary value problems are also sometimes called field problems. The field is the domain of interest and most often represents a physical structure.

The field variables are the dependent variables of interest governed by the differential equation. The boundary conditionsare the specified values of the field variables (or related variables such as derivatives) on the boundaries of the field. Depending on the type of physical problem being analyzed, the field variables may include physical displacement, temperature, heat flux, and fluid velocity to name only a few. 
International Journal of Design and Manufacturing Technology (IJDMT), ISSN 0976 6995(Print), ISSN 0976 - 7002(Online) Volume 4, Issue 2, May - August (2013), () IAEME

\subsection{Static structural analysis of Excavator arm}

The steps involved in static structural analysis are as follows :

- The IGES file of the Excavator arm is imported and geometry is generated.

- The joint connection type used in the Mechanism Design to place a component in an assembly is specified.

- Meshing of the model is done.

- Fixed support is provided to the mechanism.

- The initial digging force of $10300 \mathrm{~N}$ is applied first and then the newly calculated digging force of $7626 \mathrm{~N}$ is applied.

- Solution of the problem is done in which the stresses induced due to the force applied is found.

The fig. 3 and fig. 4 shows the stresses developed due to application of $10300 \mathrm{~N}$ force and $7626 \mathrm{~N}$ force respectively.

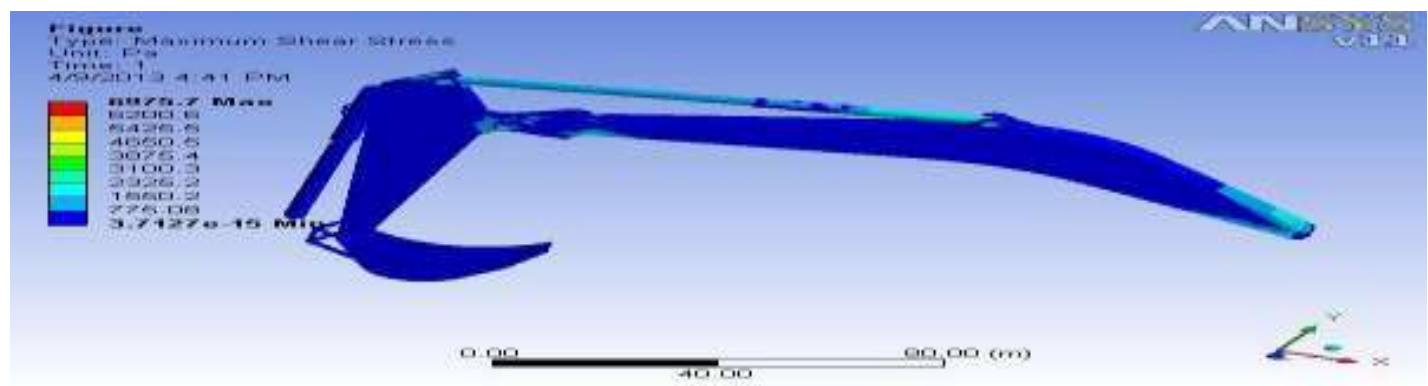

Fig.3 Maximum Shear Stress at 10300N digging force

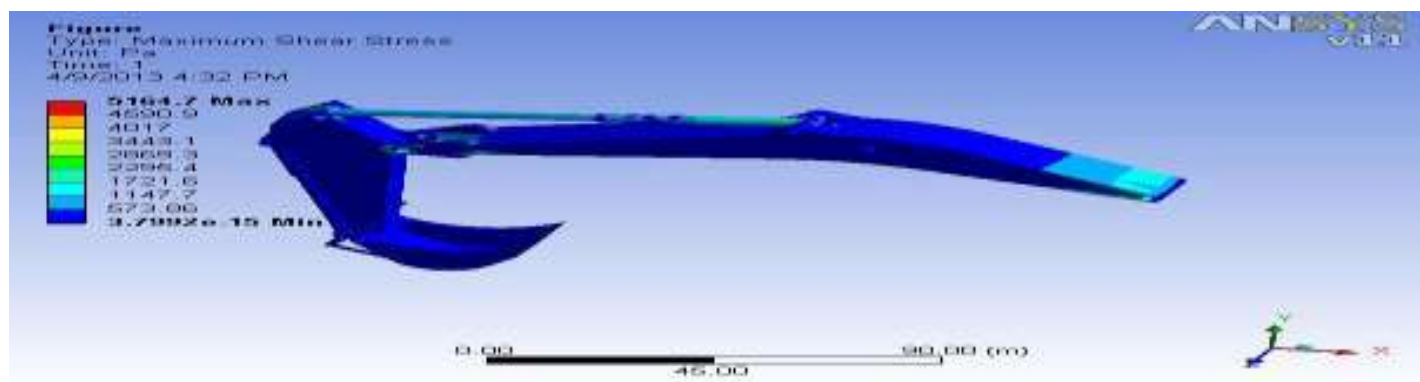

Fig.4 Maximum Shear Stress at 7626N digging force

It is seen from the fig. 3 and fig. 4 that dislocation of pin at the bucket end is occurring at $10300 \mathrm{~N}$ digging force and when the digging force is reduced to $7626 \mathrm{~N}$, the dislocation is eliminated. Also, the digging force $7626 \mathrm{~N}$ is greater than the resistive force offered by the soil surface which is $4000 \mathrm{~N}$. Hence, the design is safe.

\subsection{Dynamic analysis of bucket}

After the digging operation the bucket will lift the material. So, the total load acting on bucket will be the sum of self weight of bucket and total weight of material in the bucket. The load acting on bucket while working is $568.62 \mathrm{~N}$. Hence, the dynamic analysis of bucket is done by applying a load of $570 \mathrm{~N}$. The steps involved in dynamic analysis are as follows :

- Defining the geometry of bucket.

- Meshing of the geometry is done. The component is divided into 2147 elements having 4457 nodes. 
International Journal of Design and Manufacturing Technology (IJDMT), ISSN 0976 6995(Print), ISSN 0976 - 7002(Online) Volume 4, Issue 2, May - August (2013), () IAEME

- Providing fixed support at one end of the bucket.

- Applying force on the bucket.

- Solution involves determination of the stresses occurred due to the application of load and also finding out the total deformation.

The fig.5, fig.6, and fig.7 shows equivalent (Von-Mises) stress, Maximum Shear stress and total deformation respectively which are developed because of the $570 \mathrm{~N}$ force applied.

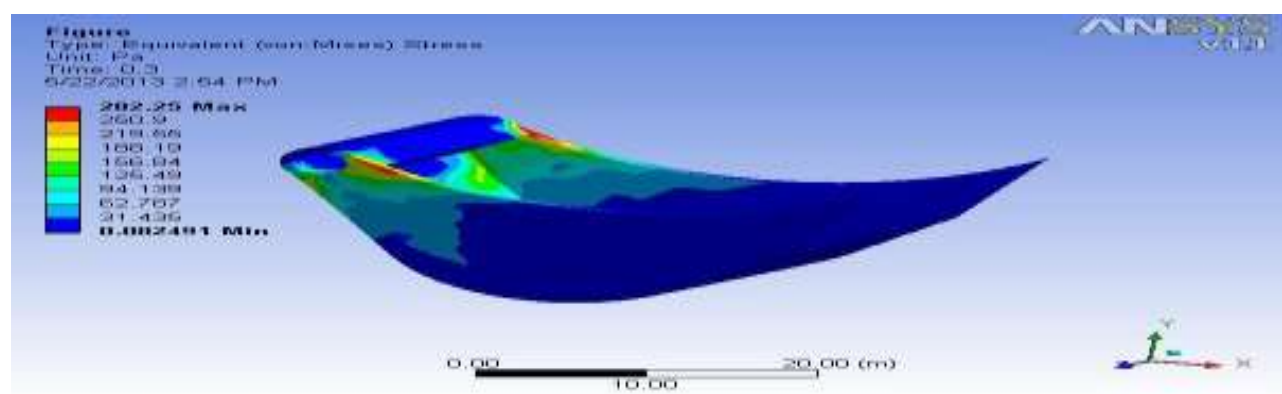

Fig.5 Equivalent (Von-Mises) Stress

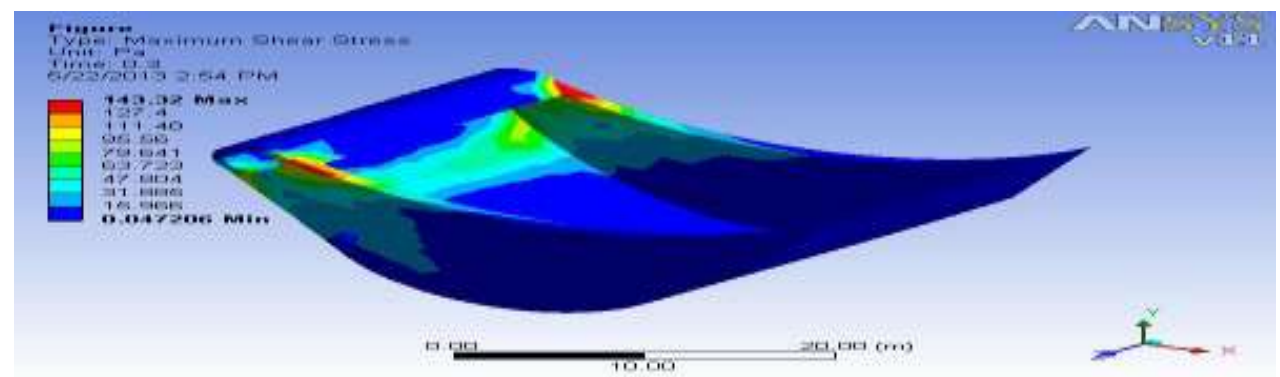

Fig.6 Maximum Shear Stress

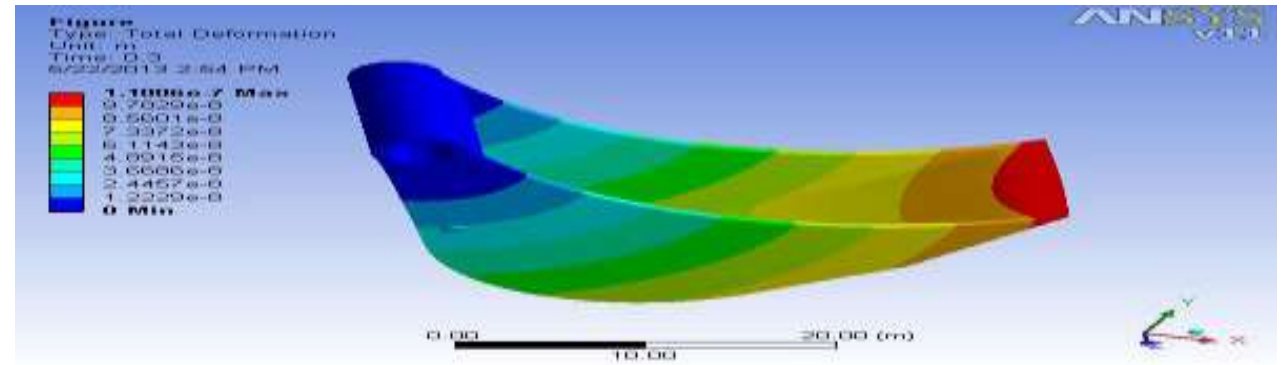

Fig.7 Total Deformation

\section{RESULTS AND DISCUSSIONS}

The static structural analysis of the excavator arm is done and the maximum shear stress developed in the model is shown. Also, the dynamic analysis of the bucket is done when the Excavator is working. The stresses developed and deformation occurred is also shown in the models of the bucket. The graphs of various stresses and deformation is drawn with respect to the time interval and are shown in the fig. 8 , fig. 9 and fig. 10 respectively. 
International Journal of Design and Manufacturing Technology (IJDMT), ISSN 0976 6995(Print), ISSN 0976 - 7002(Online) Volume 4, Issue 2, May - August (2013), () IAEME

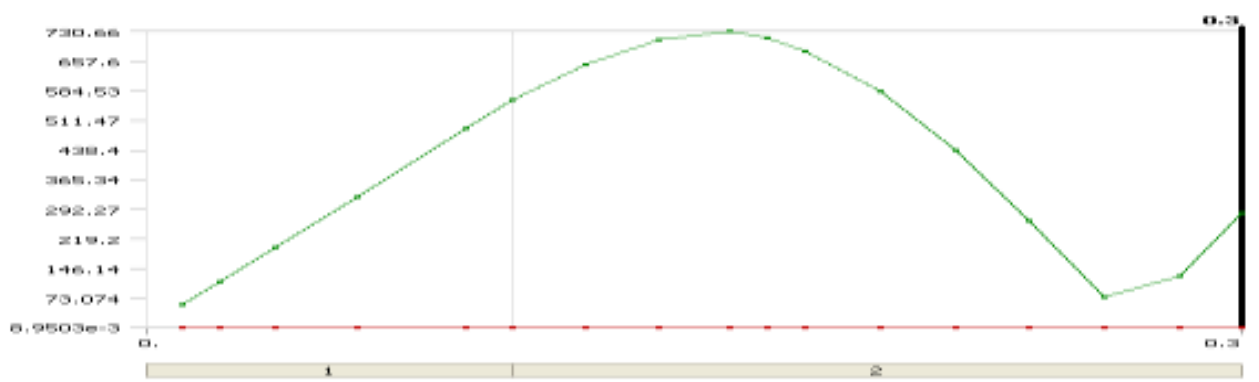

Fig.8 Graph showing equivalent (Von-Mises) stress

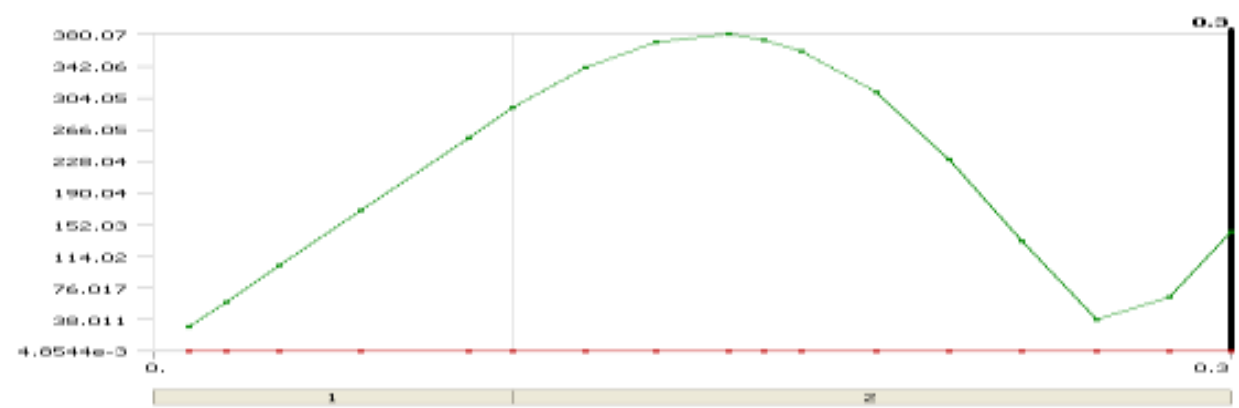

Fig.9 Graph showing maximum shear stress

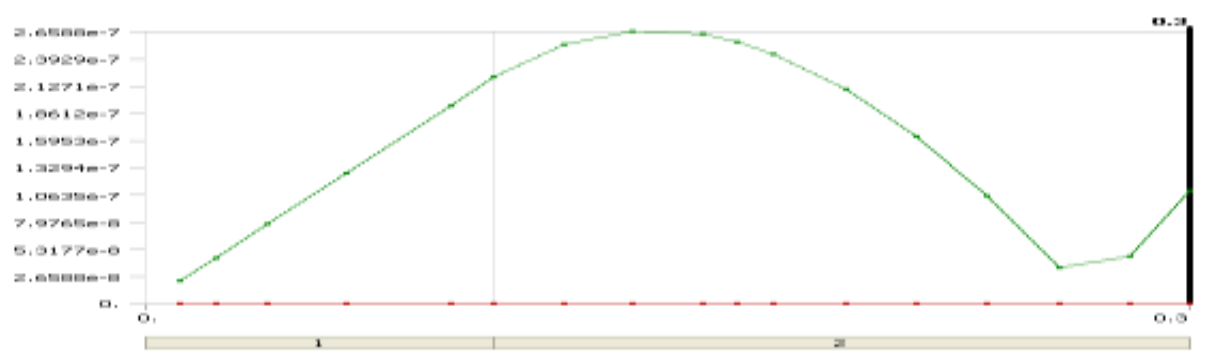

Fig.10 Graph showing total deformation

The comparison of the proposed model with the existing model is shown in the table 1.

\begin{tabular}{|c|c|c|}
\hline Description & Existing model & Proposed model \\
\hline Arm length & $650 \mathrm{~mm}$ & $723 \mathrm{~mm}$ \\
\hline Boom length & $1400 \mathrm{~mm}$ & $1347 \mathrm{~mm}$ \\
\hline Overall height & $2150 \mathrm{~mm}$ & $1996 \mathrm{~mm}$ \\
\hline Bucket capacity & $0.22 \mathrm{~m}^{3}$ & $0.28 \mathrm{~m}^{3}$ \\
\hline & $32.186 \mathrm{Kg}$ & $40.964 \mathrm{~kg}$ \\
\hline Digging force & $10300 \mathrm{~N}$ & $7626 \mathrm{~N}$ \\
\hline Max. Shear Stress & $6975.7 \mathrm{~Pa}$ & $5164.7 \mathrm{~Pa}$ \\
\hline Total Deformation & $2.8178 \mathrm{e}^{-005} \mathrm{~m}$ & $2.0863 \mathrm{e}^{-005} \mathrm{~m}$ \\
\hline
\end{tabular}

Table 1. Comparison of Proposed model with the Existing model

Thus, it can be seen from the results that the digging force can be reduced by doing some changes in the geometry of the Excavator arm. From the table 1, it can be seen that the arm length is increased in the proposed model, and the length of boom and overall height of the structure is slightly reduced. 
International Journal of Design and Manufacturing Technology (IJDMT), ISSN 0976 6995(Print), ISSN 0976 - 7002(Online) Volume 4, Issue 2, May - August (2013), (C) IAEME

\section{CONCLUSION}

Design of the excavator arm has been modified and analysis of the design is also done. From the analysis results, it is proved that the design is safe for the calculated digging force. During designing of excavator arm, the important factors taken into account are productivity and fuel consumption. Since, dislocation of the pin at bucket end and the cracking at the adapter end is eliminated by reducing the digging force. But reduction in digging force directly affects the productivity. So, the bucket capacity is increased to compensate for the loss in production due to the reduction in digging force. Also, fuel consumption is less due to the reduction in digging force. Finally, the results of the proposed model is compared with the existing model.

\section{REFERENCES}

\section{Research papers}

[1] Enrique Busquets, 'Finite Element Method Applied to a conceptual design of a Hydraulic Excavator arm', The University of Texas at El Paso International Test and Evaluation Association.

[2] Guohua Cui and Yanwei Zhang, 'Integrated Finite Element Analysis and Experimental Validation of an Excavator Working Equipment', IEEE 2009.

[3] Luigi Solazzi, 'Design of aluminium boom and arm for an excavator', Journal of Terramechanics 47 (2010) 201-207.

[4] Srdan M. Bošnjak, 'Comments on "Design of aluminium boom and arm for an excavator", Journal of Terramechanics 48 (2011) 459-462.

[5] Shahram Tafazoli, Peter D. Lawrence, and S. E. Salcudean, 'Identification of Inertial and Friction Parameters for Excavator Arms', IEEE TRANSACTIONS ON ROBOTICS AND AUTOMATION, VOL. 15, NO. 5, OCTOBER 1999.

[6] Yahya H. Zweiri, Lakmal D. Seneviratne and Kaspar Althoefer, 'A Generalized Newton Method for Identification of Closed-chain Excavator Arm Parameters', Proceedings of the 2003 IEEE lnlernstional Coorerenee on Robotics \& Automation Taipei, Taiwan, September 14-19, 1003.

[7] Chang Lv and Zhang Jihong, 'Excavating force analysis and calculation of dipper handle', IEEE 2011.

[8] Dr Amged S. El-Wakeel, Dr A.E. Elawa and Y.S. Eng. El-Koteshy, "Position Control of a Single Arm Manipulator using Ga-Pid Controller", International Journal of Electrical Engineering \& Technology (IJEET), Volume 4, Issue 2, 2013, pp. 120 - 135, ISSN Print : 0976-6545, ISSN Online: 0976-6553.

[9] Srushti H. Bhatt, N. Ravi Prakash and S. B. Jadeja, "Modelling of Robotic Manipulator ARM", International Journal of Mechanical Engineering \& Technology (IJMET), Volume 4, Issue 3, 2013, pp. 125 - 129, ISSN Print: 0976 - 6340, ISSN Online: 0976 6359.

\section{Books}

[1] A textbook of Theory of Mechanisms and Machines by Amitabha Ghosh.

[2] A Textbook of "Introduction to "Finite Elements in Engineering" by Tirupati R. Chandrupatla and Ashok D. Belegundu. Prentice-Hall of India Pvt. Ltd. 